\title{
'I didn't want her to panic': unvoiced patient agendas in primary care consultations when consulting about antidepressants
}

\author{
Alice Malpass, David Kessler, Deborah Sharp and Alison Shaw
}

\begin{abstract}
Background

Patient participation in primary care treatment decisions has been much debated. There has been little attention to patients' contributions to primary care consultations over a period of time, when consulting about depression and its treatment with antidepressants.

Aim

To explore: (1) what issues remain unsaid during a primary care consultation for depression but are later raised by the patient as important during a research interview; (2) patients' reasons for non-disclosure; (3) whether unvoiced agendas are later voiced; and (4) the nature of the GP-patient relationship in which unvoiced agendas occur.

Design of study

Qualitative interview study.

Setting

Primary health care.

Method

Patients were recruited through six general practices in the south west of England. Qualitative interviews were carried out with 10 'pairs' of GPs and patients who presented with a new or first episode of moderate to severe depression and were prescribed antidepressants. Follow-up patient interviews were conducted at 3 and 6 months. Throughout the 6-month period, patients were invited to record subsequent consultations (with GPs' consent), using a patient-held tape recorder.

Results

Twenty-three unvoiced agendas were revealed, often within decision-making relationships that were viewed in positive terms by patients. Unvoiced agendas included: a preference for immediate treatment, a preference to increase dosage, and the return or worsening of suicidal thoughts. In some cases, patients were concerned that they were 'letting the GP down' by not being able to report feeling better.

\section{Conclusion}

Unvoiced agendas are not necessarily an indication that 'shared decision making' is absent but may in some cases represent patients' attempts to 'protect' their GPs.

Keywords

decision making; depression; qualitative research.
\end{abstract}

\section{INTRODUCTION}

Involving depressed patients in treatment decisions has positive effects on treatment acceptance and clinical outcome. ${ }^{1}$ However, no qualitative work has examined patients' contributions to primary care consultations over time, when consulting about depression and treatment with antidepressants.

The importance of valuing the patients' role in consultations has been emphasised in health services research, including a trial of self-completed agenda forms in primary care, ${ }^{2}$ and qualitative work on patients' role in decisions about medication, ${ }^{3}$ as well as conceptual work that explores what shared decision making actually means in practice..$^{4,5}$

Key to debates about patients' contributions to primary care consultations is the concept of 'unvoiced agendas', which act as barriers to patient involvement. $^{6,7}$ The definition of patient agenda, as used in this paper, is shown in Box 1. Within the time constraints of a typical physician-patient encounter, the full patient agenda will rarely be voiced; some agendas may 'emerge' during the course of the consultation, ${ }^{8}$ while other types of agenda may be voiced by the patient but disregarded by physicians. ${ }^{9}$

Decision making has an added level of complexity when patients consult for depression, as the inability to contribute to or make decisions is often a symptom of untreated depression. ${ }^{10,11}$ Patients' preferences for

A Malpass, BA, PhD, NIHR research fellow; D Kessler, $M D$, MRCGP, MRCPsych, senior clinical lecturer; D Sharp, MD, FRCGP, professor; A Shaw, BA, MSc, PhD, senior lecturer, School of Social and Community Medicine, University of Bristol, Bristol.

Address for correspondence

Dr Alice Malpass, Academic Unit of Primary Health Care, School of Social and Community Medicine, Canygne Hall, 39 Whatley Road, Bristol, BS8 2PS.

E-mail: A.malpass@bristol.ac.uk

Submitted: 14 April 2010; Editor's response: 11 May 2010; final acceptance: 19 July 2010.

(C) British Journal of General Practice

This is the full-length article (published online 31 Jan 2011) of an abridged version published in print. Cite this article as: Br J Gen Pract 2010; DOI: 10.3399/bjgp11X556218. 
involvement in decision making may vary, both between patients and at different time points. ${ }^{10}$ Research that focuses upon one 'snapshot' consultation ${ }^{1}$ may not capture the complexity of the GP-patient relationship, that is, how it changes over the course of a new episode of depression. Equally, research that relies on patients' or clinicians' reports of decision making is limited. For example, a longitudinal study only includes accounts of decision making for depression rather than observations of actual decision-making practices. ${ }^{10}$ In contrast, combining interviews and audiorecorded consultations enables observation of what occurs in multiple GP-patient consultations over time, alongside gathering patients' perspectives on consultations during the same period.

The study aims were to examine (1) what issues remain unsaid during a primary care consultation for depression but are later raised by the patient as important during a research interview; (2) patients' reasons for non-disclosure; (3) whether unvoiced agendas are voiced in later consultations during the study period; and (4) the nature of the GP-patient relationship in which unvoiced agendas occur.

\section{METHOD}

\section{Recruitment and sampling}

Patients were recruited from six general practices in Bristol, using two methods: GP referral at the end of a consultation in which antidepressants were prescribed, and data searches for adults consulting for a new episode of depression. Patients identified by the GP as severely mentally ill, or unable to participate in face-to-face interviews in their own home, or in an interview in English, were excluded. Written patient consent was obtained at the beginning of each interview by the researcher. GP consent was obtained before patient recruitment commenced.

A pragmatic approach was adopted while seeking to include some heterogeneity among the patients recruited, for example regarding sex and age. The study aimed to recruit patients with a range of experiences and preferences regarding treatment for depression, and to include patients with varying prior experiences of depression: patients presenting with a new episode of depression (previous GP diagnosis of depression), a first presentation (previous experience of symptoms but no previous experience of seeking help from a GP), or a first episode (no previous experience of symptoms of depression).

\section{Data collection}

One researcher interviewed 'pairs' of patients and GPs separately as soon after the diagnostic consultation as possible, using a flexible topic guide (Box 2). The pairs of patients and GPs served as 'cases' of initial decision making about antidepressants.

\section{How this fits in}

Single 'snap-shot' recordings of consultations, or one-off interviews, are less likely to tap into the complexity of GP-patient communication and how decision making develops over time. Unvoiced agendas may occur within GP-patient consultations that exhibit many qualities of patient-centred decision making. Patients may 'protect' their GP from a sense of failure that treatment is not working. Conversely, GPs may invest their patients with more decision-making autonomy than patients themselves feel they possess, especially if they are presenting with a new rather than a first episode of depression.

GP interviews lasted between 15 and 30 minutes. Patient interviews lasted between 30 minutes and 2 hours, depending partially on the energy levels of the patient at the time of interview. Two follow-up patient interviews took place 3 and 6 months after the initial consultation. These time points were chosen because patients who benefit from taking antidepressants will have experienced some improvement in symptoms by 3 months, and after 6 months their need for continued treatment is likely to be reviewed. ${ }^{12}$

Throughout the 6-month period, patients were invited to record subsequent consultations in which their depression or antidepressants were discussed, using a patient-held tape recorder. The patient gave the tape recording to the GP at the end of the consultation, for collection by the researcher. Interviews and consultations were transcribed verbatim. The consultations were transcribed in sufficient detail to capture interactional aspects of talk, such as interruptions, overlapping speech, and turntaking and pauses. ${ }^{13}$

\section{Data analysis}

A preliminary thematic analysis of the entire dataset was conducted, drawing on the constant comparative method, ${ }^{14}$ using ATLAS.ti software (version 5) to aid coding and data management. Another researcher independently coded a subset of data including initial patient and GP interviews, subsequent patient interviews, and recorded consultations. An initial coding framework was discussed and agreed.

Various additional analyses were then undertaken.

\section{Box 1. Defining a patient's agenda when consulting for depression.}

- Any experience of symptoms relating to depression

- Any preference for treatment, including referrals, prescription requests for antidepressants, dosage, and type of antidepressant prescribed, and followup interval

- Broader ideas and concerns surrounding symptoms of depression and its treatment with antidepressants 


\section{Box 2. Topic guides for GPs and patients.}

\section{Patient topic guide}

- General health history

- Reasons for consulting the GP

- Feelings about diagnosis of depression

- Previous experience of depression and its treatment

- Experience of the initial consultation

- Expectations, views, and experiences of antidepressants

- Views about future care

\section{GP topic guide}

- Clinical interest and training in mental health

- Views of the role of antidepressants in treating depression in general and for the specific patient referred

- Availability of psychological therapies within the practice

- Relationship with the patient

- Views and experiences of the consultation

- Views of future care episode of depression, two with a first episode, and two with a first presentation. For details on patients' antidepressant use during the period of the study, see Table 1.

Eighteen consultations were recorded by patients, ranging from 10 to 30 minutes in length. One patient claimed to have recorded a consultation, leaving the tape with her GP as stated in the protocol, but this tape was not available for collection by the researcher. Twenty-three unvoiced agendas were identified, that is, issues of concern to patients that were not raised with their GPs. These have been have ordered in terms of various decisions a patient may make during their 'medication career' (Table 2), ${ }^{11}$ and in terms of the 'type' of unvoiced agenda (Table 3). Nine of the 23 unvoiced agendas occurred around deciding to start antidepressant treatment, three of which were unvoiced preferences for a prescription of antidepressants.

Continuity of care in the GP-patient relationship is seen as important in determining the 'depth' of the relationship. ${ }^{15}$ None of the unvoiced agendas occurred where the GP considered the patient to be well-known at the beginning of the study, while 15 of the 23 unvoiced agendas occurred within a new GP-patient relationship (Table 2). Of the 23 unvoiced agendas, 16 remained unvoiced throughout the study.

The four study aims are discussed in relation to three 'case studies' of unvoiced agendas that have clinical significance (for example, suicidal ideation), or run counter to clinical expectations (for example, that patients benefit from and therefore value watchful waiting), or because the case study includes the later disclosure of an unvoiced agenda with the same or a different GP. The quotations have been selected as representative of each GP-patient pair. analysed, noting if reasons for non-disclosure changed over time. To address the third aim, all consultations for each 'case' were examined to see if unvoiced agendas are voiced during later consultations. To address the fourth aim, the interview data from each GP-patient pair were compared to explore the nature of the GP-patient relationship in which unvoiced agendas occurred, identifying areas of match and mismatch within their respective perceptions of the consultations, including how decisions were made. The consultation data were also studied for examples of how GP-patient communication occurred, including whether patient preferences were explored and given legitimacy.

\section{RESULTS}

Nine GPs and 10 patients were recruited from six practices. One of the GPs referred two patients and was interviewed twice, resulting in $10 \mathrm{GP}$-patient pairs. Six patients presented to their GP with a new

\section{Case study 1: withholding the return of suicidal thoughts}

The first case study is a patient who presented with a new episode of depression to a GP who knew her, but not well. The patient had begun antidepressant treatment the same day that they were prescribed, and at 6 months had begun to reduce dosage with a view to stopping. Despite disclosing suicidal thoughts at the diagnostic consultation, in the following 3 months the patient withheld the return of suicidal thoughts.

The patient described a sense of 'duty' to respond to treatment, and a feeling that by not improving she was in some way 'letting the GP down' and 'failing':

'I was dreading going and saying I don't feel better ... that was getting me down ... the pressure of having to tell someone "no I still feel terrible"; I want to say "this is really working". I 
didn't want her to panic and suddenly think "oh things have got so much worse" ... I felt I was in control of it, I didn't want her to change my medication because of it.' (patient 106C, 3-month interview)

The patient wants to protect her GP from unnecessary 'panic' and herself from the consequences of this, that is, a change in medication.

The GP credits the patient with greater autonomy in decision making than the patient herself acknowledges:

'I think she's quite able to make her own decisions, and might not necessarily take advice on it ... I think, she would listen to what I had to say but she wouldn't be completely led by me.' (GP5, interview about patient 106C)

In contrast, the patient presents herself within the research interview as wanting direction from the GP:

'I tend not to like to tell doctors what to do ... I want someone to tell me what to do ... I have always sort of thought, "right, a doctor just tells me what I have and I just say thanks and go".' (patient 106C, 3-month interview)

The patient assumes the GP may change her medication if she discloses the return of suicidal thoughts. Not disclosing how she was feeling increased the patient's sense of panic that she was not getting better and might run out of options:

'I have this panic that there's not going to be anything else to help me so I'm trying to kid myself, "it's alright, it's quite contained, just tell her everything's fine", and I haven't, I mean I've gone along and said "It's been a difficult month".' (patient 106C, 3-month interview)

This unvoiced agenda seems at odds with the apparent openness characterising communication between this GP and patient:

'As a doctor she really asks, she doesn't just ask "Is the medication okay?" she really asks how I am and how I am coping with things.' (patient 106C, 6-month interview)

Within the consultations, the patient regularly asks questions and negotiates treatment decisions. While she has not voiced the return of her suicidal thoughts, she has been able to express that she is having 'difficulty'. The consultation data show that the GP regularly restates what the patient has said, giving it
Table 1. Patients' antidepressant use during the period of the study.

Number

Antidepressant use following diagnostic consultation

Accepted prescription and started antidepressants straight away

Accepted prescription but delayed in starting antidepressants

Rejected prescription at index consultation

7

Antidepressant use after 6 months

Still taking antidepressants, began 5 months after initial consultation

Repeat prescription at same dosage

Had reduced dosage with view to stopping

Had stopped taking antidepressants

Had never taken antidepressants

Had left the country

Stopped antidepressants during first prescription with no consultation then restarted 6 months later

legitimacy. The GP regularly asks for the patient's views, before giving her own clinical perspective. She creates conditions of ease for the patient to interact, by leaving pauses to draw out the patient's experience further. Thus, in this case, the unvoiced agenda occurred within a 'patient-centred' GP-patient relationship.

\section{Case study 2: withholding a preference for immediate treatment}

This patient was referred to the GP by the health visitor, who, after completing a postnatal depression questionnaire with the patient, made an emergency GP appointment with a recommendation for antidepressants. The GP did not know the patient, and prescribed hypnotics. The patient did not voice her agendas: a preference for immediate treatment with antidepressants and a referral for counselling; her feelings about the diagnosis; and her confusion surrounding the decision to take antidepressants. A second appointment was made with a different GP who the patient expected to be 'more sympathetic' and who knew her 'reasonably well'. At this appointment, the patient did not voice her confusion surrounding antidepressant treatment, or her preference for counselling.

The patient attributed her unvoiced agendas to the GP's lack of patient-centred communication skills and her own emotional state:

'[sighs] she wasn't very ... sympathetic, and I just burst into tears as soon as I says, that I was sent over by the, health visitor [sighs]. I suppose some people you click with, some people you don't and she just seemed a bit distant ... I know she's following procedures ... it's just I expected someone to be oh, you know, and she was "right, let's start with ... sleeping tablets first and then see how"... maybe she was in a hurry ... I probably felt guilty for taking up the time, I was just crying, so 
Table 2. Patients' antidepressant use during the period of the study.

\begin{tabular}{|c|c|c|c|c|}
\hline $\begin{array}{l}\text { Trajectory of } \\
\text { medication career }\end{array}$ & Unvoiced agenda (sex) & $\begin{array}{l}\text { Longitudinal perspective: was the } \\
\text { unvoiced agenda raised later? }\end{array}$ & $\begin{array}{l}\text { GP-patient relationship } \\
\text { as defined by GP }\end{array}$ & $\begin{array}{l}\text { Episode } \\
\text { or presentation } \\
\text { of depression }\end{array}$ \\
\hline Seeking help & $\begin{array}{l}\text { 1. Feelings of 'weakness' and being } \\
\text { 'unworthy of GP time' (M) }\end{array}$ & $\begin{array}{l}\text { Disclosed when returning to a } \\
\text { different GP during relapse } 6 \text { months } \\
\text { after stopping treatment }\end{array}$ & NP & FP \\
\hline \multirow[t]{9}{*}{$\begin{array}{l}\text { Deciding to start } \\
\text { antidepressant }\end{array}$} & $\begin{array}{l}\text { 2. Preference for antidepressants } \\
\text { and referral for counselling }(F)\end{array}$ & $\begin{array}{l}\text { Disclosed at second appointment, } \\
\text { with a different GP }\end{array}$ & K & NE \\
\hline & 3. Preference for antidepressants $(F)$ & $\begin{array}{l}\text { Antidepressant prescribed in the same } \\
\text { consultation as non-disclosure }\end{array}$ & K & NE \\
\hline & $\begin{array}{l}\text { 4. Ambiguity over diagnosis and } \\
\text { treatment with antidepressants (F) }\end{array}$ & $\begin{array}{l}\text { Undisclosed; patient remained confused } \\
\text { for } 5 \text { months before deciding to start } \\
\text { antidepressant }\end{array}$ & K & NE \\
\hline & 5. Preference for a counselling referral $(F)$ & $\begin{array}{l}\text { Undisclosed for } 6 \text { months after being } \\
\text { prescribed antidepressant, and } 1 \text { month } \\
\text { after treatment began }\end{array}$ & K & NE \\
\hline & 6. Preference for antidepressants (M) & $\begin{array}{l}\text { Undisclosed; antidepressants prescribed } \\
\text { in same consultation }\end{array}$ & NP & FP \\
\hline & Fear of addiction $(F)$ & $\begin{array}{l}\text { Undisclosed; antidepressants prescribed, } \\
\text { patient started treatment but did not } \\
\text { return to GP, discontinued treatment }\end{array}$ & NP & FE \\
\hline & 8. Fears long recovery process $(\mathrm{F})$ & $\begin{array}{l}\text { Undisclosed, decided not to take } \\
\text { antidepressants for length of study }\end{array}$ & NP & $\mathrm{FE}$ \\
\hline & $\begin{array}{l}\text { 9. Ambiguity over diagnosis and } \\
\text { treatment with antidepressants }(\mathrm{M})\end{array}$ & Disclosed in follow-up consultation & NP & FP \\
\hline & 10. Symptom of sleeplessness (F) & 10. Undisclosed & NP & FE \\
\hline Dosage & No unvoiced agendas & & & \\
\hline $\begin{array}{l}\text { Type of } \\
\text { antidepressant }\end{array}$ & No unvoiced agendas & & & \\
\hline $\begin{array}{l}\text { Next appointment } \\
\text { interval }\end{array}$ & 11. Not wanting to meet so regularly $(F)$ & Disclosed in subsequent consultations. & K & NE \\
\hline $\begin{array}{l}\text { Reviewing dosage } \\
\text { (increase) }\end{array}$ & 12. Preference to increase dosage $(F)$ & Later disclosed after three consultations & K & NE \\
\hline \multirow{5}{*}{$\begin{array}{l}\text { Deciding to continue } \\
\text { antidepressant } \\
\text { treatment }\end{array}$} & 13. Worsening of suicidal thoughts (M) & $\begin{array}{l}\text { Disclosed } 6 \text { months later after stopping } \\
\text { treatment and having severe relapse }\end{array}$ & NP & FP \\
\hline & $\begin{array}{l}\text { 14. Ambivalence about treatment } \\
\text { effect }(\mathrm{M})\end{array}$ & Undisclosed & NP & FP \\
\hline & $\begin{array}{l}\text { 15. Does not share disappointment } \\
\text { 'it is not a cure' (M) }\end{array}$ & Undisclosed & NP & FP \\
\hline & 16. Return of suicidal thoughts $(\mathrm{F})$ & Undisclosed & $\mathrm{K}$ & NE \\
\hline & 17.Regular experience of panic attacks $(F)$ & Undisclosed & NP & FE \\
\hline Counselling & $\begin{array}{l}\text { 18. Reluctance to pursue counselling } \\
\text { not disclosed (F) }\end{array}$ & Undisclosed & NP & NE \\
\hline Exercise & No unvoiced agendas & & & \\
\hline \multirow[t]{2}{*}{ Deciding to stop } & $\begin{array}{l}\text { 19. Loss of libido as one factor in wanting } \\
\text { to stop treatment }(\mathrm{F})\end{array}$ & Undisclosed & $\mathrm{K}$ & NE \\
\hline & 20. Interest in continuing treatment $(\mathrm{M})$ & Undisclosed & NP & FP \\
\hline \multirow[t]{3}{*}{$\begin{array}{l}\text { Reducing dosage } \\
\text { as part of stopping }\end{array}$} & 21. Does not share worry about relapse $(M)$ & $\begin{array}{l}\text { Undisclosed, patient takes dose erratically } \\
\text { on 'bad days' }\end{array}$ & NP & FP \\
\hline & $\begin{array}{l}\text { 22. Should we have tried another } \\
\text { antidepressant? (M) }\end{array}$ & Undisclosed & NP & FP \\
\hline & $\begin{array}{l}\text { 23. Should we pursue another type of } \\
\text { treatment? (M) }\end{array}$ & Undisclosed & NP & FP \\
\hline
\end{tabular}

$F=$ female. $F E=$ first episode. $F P=$ first presentation. $K=$ known. $M=$ Male. $N E=$ new episode. $N P=$ new patient. WK $=$ well-known. 
she probably couldn't get the information out of me because I was in a bit of a state.' (patient 105C, first interview).

Six months later, the patient viewed this first consultation in the same way, perceiving a mismatch between 'clinical procedure' and her own preferences:

'I thought l'd come away with antidepressants and came away with sleeping tablets ... perhaps she felt that I needed to have a decent sleep and see how I felt after that, so maybe she didn't want to jump into things too quickly ... In some ways that was good, but at the time I think I just wanted something to make me feel better.' (patient 105C, 6-month interview)

The patient described the GP who prescribed antidepressants in more positive terms:

'... he was just on your side because he's sort of with you ... He can empathise ... I was quite determined that l'll go in and talk to him, tell him how I'm feeling ... I did explain I don't want anything too heavy but l'd like something to lift my spirits a bit ... [afterwards] I felt like l'd got the goods [laughter]. I felt like mission accomplished.' (patient 105C, first interview).

Having voiced her preference for antidepressants in this second consultation with a different GP, her confusion about whether antidepressants were the right treatment remained unvoiced. The health visitor strongly recommended antidepressants, her husband was against her taking them, and the first GP had offered sleeping pills. This confusion was exacerbated by the indecision that can characterise depression:

'... there's one person saying it's a good idea to take them and somebody saying no, you should not take them; I was in the middle and I couldn't make my mind up, I was really confused, I think I'm worse at the minute; I just can't make my own mind up.' (patient 105C, first interview)

The prescribing GP was not aware of this uncertainty:

'I didn't pick up in that consultation that she was concerned about using them ... the fact that she had used them before ... I was thinking that she would have an understanding of how they had helped her before or not helped her before and being in a position to judge whether they would be helpful.' (GP4, interview about patient 105C)
Table 3. Types of unvoiced agenda

\begin{tabular}{ll}
\hline Feelings about seeking help & $n$ \\
\hline Symptoms, excluding suicidal ideation & 1 \\
\hline Preference for antidepressant: prescription request & 3 \\
\hline $\begin{array}{l}\text { Emotions about diagnosis and antidepressants } \\
\text { (for example, ambiguity over diagnosis, }\end{array}$ & 1 \\
fears of addiction) & \\
\hline Not wanting a counselling referral & 1 \\
\hline Wanting a counselling referral & 2 \\
\hline Care plan (for example, interval for follow-up) & 1 \\
\hline Dosage & 1 \\
\hline Suicidal ideation & 2 \\
\hline $\begin{array}{l}\text { Emotions about recovery process } \\
\text { (for example, disappointment, ambivalence, worry) }\end{array}$ & 6 \\
\hline
\end{tabular}

The GP can be seen to have over-invested the patient with autonomy in decision making, based on a previous history of depression and use of antidepressants.

The patient did not start antidepressants until 5 months after they were prescribed and did not return to her GP before making this decision. For the intervening 5 months she remained perplexed:

'What can they say to me if I go back and say "I haven't taken the tablets but I still feel down" ... they'll probably say "Take the tablets" [laughter] ... they might just think why am I back in the surgery ... will I look a fool if I go back? I don't know ... the feeling l've got is that they happily give you tablets but they won't recommend things like counselling.' (patient 105C, first interview)

Not voicing her confusion about antidepressants impacted subsequent treatment decisions, including further help seeking and exploration of other treatment preferences such as counselling.

The patient saw her difficulty in making decisions and asserting herself as characteristic of her depression, and so she struggled to share her preferences. The consultations were experienced as rushed, and she felt that GPs did not discuss various treatment options. She had not felt able to make treatment suggestions because she saw the GP as the 'expert': 'I do feel a bit humbled by them, I daren't suggest things'. She also felt she had wanted the GP to take control: 'sort of expected the doctor to make the decision for us' (patient 105C, first interview).

\section{Case study 3: withholding a preference to increase the dosage of antidepressants}

This patient presented with a new episode of depression, to a GP who had seen her 10 times in the 
previous 18 months. She was prescribed antidepressants and started them straight away. After 2 months of treatment, the patient wanted to increase the dosage from $20 \mathrm{mg}$ to $30 \mathrm{mg}$. This was an unvoiced agenda that was undisclosed for two consecutive consultations.

At the 3-month and 6-month interviews, this patient characterised herself as 'deferential':

'... she kept sort of going through the various options and kept avoiding going up dosage and I kept thinking "well I think I need to", but then I always have something my mother's instilled in me "Don't tell a doctor what to do".' (patient 109C, 3-month interview)

In contrast, the GP viewed the patient to be much more confident in making autonomous decisions:

'... she is a person who knows what she wants ... she's the sort of person that will make her own decisions.' (GP5, interview about patient 109C)

Both the patient and the GP thought that the other was reluctant to increase dosage, so avoided suggesting it. After two consultations where this agenda remained unvoiced, the patient finally voiced her concerns tentatively:

'But I don't know [hesitation] if there's an issue on dosage or not?' (patient 109C, third consultation)

Subsequent increases in dosage (of which there were two) were suggested by the GP. During the second of these, the patient deferred to the GP entirely: 'l'd like you to decide' (patient 109C, fourth consultation).

One effect of the unvoiced agenda in this case is a delay in increase in dosage. The occurrence of the unvoiced agenda is surprising in this GP-patient pair because the relationship is characterised by 'patientcentred' communication. For example, the GP ensures early on that the patient realises they have control of the treatment decision:

Patient: 'So shall I just carry on with this [dosage]?'

GP: 'Well at the end of the day it's up to you, but yes l'd say carry on a bit longer and I think it will help answer your questions [about latency in the recovery process].' (patient 109C and GP5, first consultation)

Throughout the 6-month study period, the GP encourages the patient to trust her own judgement.

The underlying reason for the unvoiced agenda appears to be a mismatch in their perceptions of each others' decision-making role. The patient wants to defer decisions on dosage to the GP, while the GP perceives the patient to be more autonomous and able to take control of treatment decisions than she perceives herself to be:

'I want that guidance really which I don't necessarily get ... I want someone to say, "this is what you need, this will make you feel better".' (patient 109C, 3-month interview)

The GP's view of the patient's autonomy may be due to knowledge of the patient's previous history of depression and treatment with antidepressants.

\section{DISCUSSION}

\section{Summary of main findings}

The study findings provide various patient-based explanations for unvoiced agendas. In case study 1 , the patient's withholding of suicidal thoughts was a way of maintaining control of medication management. It was also a way for the patient to 'look after' the GP. The patient withheld symptoms, to protect her GP from 'panic' and a sense that the treatment was not working. For the other patients, their symptoms acted as barriers to meaningful contribution to the consultation, for example, indecision and a sense of being a 'fraud'. This was compounded by GPs failing to take these symptoms into account when trying to enable patients to feel at ease to interact. In other cases, unvoiced agendas occurred as a result of a mutual misconception: the patient holding a traditional 'the doctor knows best' mindset, and the GP overestimating the patient's own sense of 'autonomy'.

The study findings tell us something about the characteristics of the GP-patient relationship in which unvoiced agendas occur. Unvoiced agendas often occurred within decision-making relationships that were described in positive terms by patients, where patient's agendas were regularly explored and given legitimacy by GPs. This suggests that unvoiced agendas do not always reflect poor communication skills on the part of GPs, or a lack of patient-centred care.

\section{Strengths and limitations of the study}

The longitudinal design of the study afforded an opportunity to discover whether unvoiced agendas are later voiced in subsequent consultations. Defining an unvoiced agenda and identifying when it happens in practice is challenging. The researchers asked patients about unvoiced agendas at interview and explored the significance of these agendas. The analysis reviewed whether or not the unvoiced 
agenda had been raised at a later consultation and whether it had impacted on any decision or outcome. The later voicing of previously unspoken agendas highlights that patient-GP communication and decision making is a process. Analysing single encounters between patients and GPs has been a limitation of previous cross-sectional research on decision making within consultations, as noted by others. $^{16}$

Patients were asked to record consultations when they consulted for depression and its treatment, and were only questioned about this type of consultation in the interviews. Other unvoiced agendas relating to other conditions might have occurred during the study period. By asking patients to record their GP consultations, the study will have shaped the GP-patient interactions within those consultations. The follow-up patient interviews may have prompted disclosure of previously unvoiced agendas. Patient recall bias may be an issue, particularly as patients with depression can have difficulties relating to memory and concentration. The limitations of recruitment to this study have been reported elsewhere. ${ }^{17}$

\section{Comparison with existing literature}

GPs in the study sample sometimes overinvested patients with the autonomy and capacity to make decisions regarding treatment; autonomy that patients felt they lacked. This is more likely to occur when a patient presents with a new episode of depression and previous experience of taking antidepressants, and the GP assumes that the patient will be better placed to make a treatment decision. This GP behaviour might be conceptualised as a type of 'inverse paternalism'. Instead of adopting a traditional 'paternal' role and making decisions on behalf of the patient, the GP acts with an inverted paternalism; expecting the patient to lead on and make decisions regarding treatment. This is distinct from the 'patient-centred' decision-making model in which both parties agree in according a more active role to the patient in defining the problem and determining appropriate treatment. ${ }^{16}$ 'Inverse paternalism' is characterised by a mismatch between the patient's and GP's perception of the decision-making relationship, with inaccurate assumptions about the role each is to take. This contrasts with 'patient-centred' decision making, in which the patient's active lead in decision making has been clearly established. ${ }^{18}$

Existing literature suggests that GPs and patients both have unspoken and sometimes inaccurate assumptions about each other and the decisions that have been made. ${ }^{3}$ With pairs of GP and patient interviews conducted shortly after a diagnostic consultation in which an antidepressant was prescribed, it was possible to gain both patients' and GPs' views of what happened in the first consultation, identifying both convergence and mismatch of perceptions of how decisions were made. This has provided a rich context for analysing the occurrence of unvoiced agendas.

\section{Implications for clinical practice and future research}

The 'good patient' is often described in the literature as someone who is an 'active partner' in decision making. ${ }^{18,19}$ The concept of the 'good patient' is problematic for patients presenting with depression, whose low self-esteem and indecision may make contributing as an active partner challenging. When a patient presents with a new episode of depression and previous experience of taking antidepressants, it is important for GPs to explore the degree to which patients wish to be involved in decision making, discriminating between passivity as preference and passivity as a symptom.

Identifying 'passivity as preference' involves discriminating whether patient preference is based on paternalism ('don't tell a doctor what to do') or fear of the power imbalance ('I daren't suggest things'), or based upon a genuine preference and expectation ('I want you to decide'). This raises the question, is it ever patient centred to be doctor centred? ${ }^{20}$ The findings of this study suggest it is; if the request has come from the patient. Skelton makes the helpful distinction between 'doing patient centredness' and 'being patient centred'. ${ }^{20}$ This study found that when GPs are being patient centred, patients feel they are not losing any control over their health by asking the GP to decide.

\section{Funding body}

The study was funded by the National Institute of Health Research.

\section{Ethics committee}

The study was approved by the Southmead Research Ethics Committee (07/Q2002/14).

\section{Competing interests}

The authors have stated that there are none.

\section{Acknowledgements}

We would like to thank all the participating patients, doctors, and practice staff.

\section{Discuss this article}

Contribute and read comments about this article on the Discussion Forum: http://www.rcgp.org.uk/bjgp-discuss

\section{REFERENCES}

1. Loh A, Simon D, Hennig K, et al. The assessment of depressive patients' involvement in decision-making in audio-taped primary care consultations. Patient Educ Couns 2006; 63(3): 314-318.

2. Little P, Dorward M, Warner G, et al. Randomised controlled trial of effect of leaflets to empower patients in consultations in primary care. BMJ 2004; 328(7437): 441

3. Stevenson FA, Barry CA, Britten N, et al. Doctor-patient communication about drugs: the evidence for shared decision- 
making. Soc Sci Med 2000; 50(6): 829-840.

4. Charles C, Gafni A, Whelan T. Shared decision making in the medical encounter: what does it mean? (or it takes two to tango). Soc Sci Med 1997; 44(5): 681-692.

5. Charles C, Gafni A, Whelan T. Decision-making in the physician-patient encounter: revisiting the shared treatment decisionmaking model. Soc Sci Med 1999; 49(5): 651-661.

6. Barry CA, Bradley CP, Britten N, et al. Patients' unvoiced agendas in general practice consultations: qualitative study. $B M J$ 2000; 320(7244): 1246-1250.

7. Hamilton W, Britten N. Patient agendas in primary care. BMJ 2006; 332(7552): 1225-1226.

8. Peltenburg M, Fischer JE, Bahrs O, et al, for the investigators of the Euro-Communication Study. The unexpected in primary care: a multicenter study on the emergence of unvoiced patient agenda. Ann Fam Med 2004; 2(6): 534-540.

9. Salmon P, Dowrick C, Ring A, Humphri G. Voiced but unheard agendas: qualitative analysis of the psychosocial cues that patients with unexplained symptoms present to general practitioners. $\mathrm{Br} \mathrm{J} \mathrm{Gen}$ Pract 2004; 54(500): 171-176.

10. Garfield S, Francis F, Smith S. Building concordant relationships with patients starting antidepressant medication. Patient Educ Couns 2004; 55(2): 241-246.
11 Malpass A, Shaw A,Walter F, et al. 'Moral career or medicine career?' The two sides of managing antidepressants, a meta-ethnography of patients' experience of anti-depressants. Soc Sci Med 2009; 68(1): 154-168.

12. Anderson IM, Nutt DJ, Deakin FW. 1993 British Association for Psychopharmacology guidelines. J Psychopharmacol 2000; 14(1): 3-20.

13. Atkinson JM, Heritage J. Structures of social action: studies in conversational analysis. Cambridge: Cambridge University Press, 1984.

14. Strauss A, Corbin J. Basics of qualitative research: techniques and procedures for developing grounded theory. London: Sage, 1998.

15. Ridd M, Shaw A, Lewis G, Salisbury C. The patient-doctor relationship: a synthesis of the qualitative literature on patients' perspectives. Br J Gen Pract 2009; 59(561): 268-275.

16. Charles C, Gafni A, Whelan T. How to improve communication between doctors and patients. BMJ 2000; 320(7244): 1220-1221.

17. Malpass A, Heawood A, Kessler D, Sharp D. Concordance between PHQ-9 scores and patients' experiences of depression: a mixed methods study. Br J Gen Pract 2010; 60(575): 231-238.

18. Jadad AR, Rizo CA, Enkin MW. I am a good patient, believe it or not. BMJ 2003; 326(7402): 1293-1295.

19. Ellner A, Hoey A, Frisch L. Speak up! BMJ 2003; 327(7410): 303-304.

20. Skelton J. Language and clinical communication: this bright Babylon. Oxford: Radcliffe Publishing, 2008. 